\title{
The Intrinsic Logics of English Phonics Learning Among Chinese School-Age Children
}

\author{
Huanhuan $\operatorname{Ren}^{1, \mathrm{a}^{*}}$ and Chi Ma ${ }^{2, \mathrm{~b}}$ \\ 1 Teaching and Research Institute of Foreign Languages, Bohai University, Jinzhou 121013, China \\ 2 Jinzhou Institute of Forestry Research, Jinzhou Forestry Bureau, Jinzhou 121013, China \\ arenhuanhuan2014@163.com, bmachi2014@tom.com
}

\section{Keywords: English Phonics; Intrinsic Logics; School-age Children}

\begin{abstract}
Phonics can be interpreted from three areas of learning, namely, letters and sounds, words and activities, reading and success. The main significance of English phonics learning among Chinese school-age children are different from that among native young learners, exerting positive effects on two aspects of learning performance, which are enhancing phoneme and phonemic awareness as well as boosting listening and speaking confidence among Chinese school-age children. In this regard, the intrinsic logics of cultivating English phonics among Chinese school-age children is supposed to obey to four basic rules for success in phonics learning, that is, the input of phonemes through phonics drill, the clear pronunciation through listening practice, the word cognition through audio material, and the increased vocabulary through autonomous reading. It's hoped that this research provides a useful reference for future phonics instruction and learning practice among young English language students in China.
\end{abstract}

\section{Introduction}

For decades now, the teaching and learning of phonics has been the subject of debate[1]. Experts argue about how much emphasis should be placed on phonics instruction, but just about all agree that phonics is one of the aspects of literacy critical to successful literacy learning[2]. Much doubts have to be levelled to the importance of phonics especially among EFL learners, including Chinese school-age children. Take some instances. Is it true for Chinese school-age children to start English study from learning phonics? Do Chinese school-age children benefit from learning phonics in literacy development just as native young learners do? What are the ideas or wisdoms behind English phonics instruction and learning among Chinese school-age children? This thesis aims at finding out the intrinsic logics of English phonics learning among Chinese school-age children, based on the interpretation of phonics learning process and the analysis of the main significance of English phonics learning among Chinese school-age children. This paper is a summary of this research work, which hopefully provides a useful reference for future phonics instruction and learning practice among young language students in China.

\section{The Interpretation of Phonics Learning Process}

Letters and Sounds. What is phonics? The prefix of phon stands for things related to sound, such as phone, microphone and phonics, to name just a few. It's easy to find that phonics is all about teaching children the sounds in English words. There are 26 letters of the alphabet, which can be manipulated to make 44 sounds. Of these 44 sounds, 19 are vowel sounds (which are most commonly represented by the symbols $a, e, i, o, u$ ), while 25 are consonant sounds(which are most often represented by symbols $b, c, d, f, g, h, j, k, l, m, n, p, q, r, s, t, v, w, x, y \& z$, and the letter $y$ can make a consonant and vowel sound)[3]. If a phoneme is the smallest unit of sound that can differentiate meaning, then a grapheme is the smallest unit of written language that can differentiate meaning[4]. A grapheme could be a letter or a symbol. It's believed that, by playing around with these 26 letters, through phonics, learners can learn the 44 phonemes. For example, $c$ can make two sounds, with /k/ as in "cat" and /s/ as 
in "city". With phonics, children can have the competence to know relationships between letters and sounds especially know rules for vowels, consonants, and blends along with practice.

Words and Activities. What's the significance of the correspondent connection between letters and sounds? With basic phonics concepts and knowledge in mind without struggle or frustration, children have to get to know how to use it to recognize words when reading, and to spell words when writing. In other words, learners are expected to possess the skills of blending and segmenting. Phonetic blending or called decoding is the ability to join phonemes in a smooth enough manner to approximate a pronunciation that enables identification of the word[5]. If blending is not mastered, students may develop proficient phonemic awareness but struggle to combine individual sounds into words[6]. For example, when reading the word plum, children are able to sound out $p l-u-m$ rather than any other pronunciation. Segmenting or encoding is the main skill for writing of being able to hear the sounds in words and knowing how to write the appropriate letter(s) for those sounds. Dog is made of $d-o-g$, for example. Giving students more opportunities to play with and manipulate words in a fun and engaging way will deepen their knowledge of how letters and sounds make words. Besides phonically regular words, tricky words or sight words which are difficult for children to learn to spell but with high frequency in easy texts should be also learned by heart by learners, so as to go with the process of independent reading.

Reading and Success. After the focus on the fundamentals of reading and spelling from vowel sounds to sight words, what will phonics help learners do next? Phonics is absolutely essential for helping children begin to read because phonics series emphasizes the key phonics skills that children need to know to become independent readers. If learners are found to identify sounds in words and sentences, they are well on their way to become literate. Beginning readers must become familiar with the printed code in order to equate it with oral language[7]. Young children can understand and enjoy a book if someone reads the text to them; however, in order to understand and enjoy the book on their own, they must learn to recognize printed words as the equivalent of what was read to them[8]. It's argued that the more students are provided with scaffolded opportunities to practice their phonics learning in authentic reading and writing contexts, the more successful they will be in applying and transferring this knowledge[9]. Equally, phonics, in return, should be taught explicitly and systematically as part of a balanced and integrated literacy program[10]. Additional literature and helpful suggestions are also supposed to be delivered to learners to further enhance and cultivate their appreciation of reading. It's found that once the code of reading has been cracked through phonics, children will then have the ability to explore the length and breadth of literacy as a whole[11].

\section{The Main Significance of English Phonics Learning among Chinese School-age Children}

Phoneme and Phonemic Awareness. Learning phonics is a big help for Chinese school-age children to master the basic phonemes of English language. As we know that all English words are made up of sounds, and phoneme is a single unit of sound that has meaning in English language[12]. Through phonics learning, Chinese school-age children can get in touch with a body of knowledge about grapheme and phoneme, namely letters and sounds, especially the letter-sound correspondent connection. Over time, learners would be likely to possess the ability of phonemic awareness to hear, identify, and manipulate individual sounds-phonemes in spoken words. This skill is very critical for every English learner, especially for the EFL learner who have fewer opportunities to get access to native speakers. It's concurred that the best start to cultivate phonemic awareness is among young children. The wisdom behind it is that younger learners are particularly savvy at capturing and repeating speech sounds of a foreign language[13]. Without a large amount of phoneme practice at the critical period of language learning time, learners may feel frustrated in following learning especially listening and speaking and hard to succeed in recognizing different phonemes and even forming phonemic awareness.

Listening and Speaking Confidence. Benefits can accrue to learners who have explored and mastered the phonics knowledge. It's found that instructors embrace phonics in the classroom based on the promise that it can have an positive effect on reading comprehensive abilities of younger 
learners[14]. However, as for the implications and insights given into EFL learners, researchers have different opinions. Researchers and educators agree on the idea of phonics and discover phonics instruction as an English teaching instruction not only for young native speakers but also for EFL learners[15]. However, it's argued that phonics instruction can help EFL students to improve their listening and speaking skills, together with their pronunciation and intonation[16]. This argument can be easily understood considering the different English language environment EFL children and native speakers are involved in. Native speaks are exposed to authentic English language when they are born, and their life is replete of different English sounds from parents, friends and teachers etc[17]. The phonics learning to native speakers is just to connect the word sounds heard in daily life with word forms strange to them, in the hope that they could ultimately go for further autonomous reading with increased vocabulary[18]. However, the values of phonics learning for EFL learners lie in the confidence in having a good command of English listening and speaking.

\section{The Intrinsic Logics of English Phonics Learning among Chinese School-age Children}

The Input of Phonemes through Phonics Drill. Parents and teachers should do everything they could to help Chinese children get access to the a large amount of phonemes. The start point for young learners is to get to know the 44 phonemes in English, with each one representing a different sound a person can make. There are no better material to learn English phonemes than a variety of quality phonics resources. It's claimed that the main channels for English phonics learning among Chinese school-age children are various, including interactive Apps in smart devices, multi ROMs and videos, phonics-focused animated cartoons, series of phonics textbooks, picture books and leveled books, and courses provided by language training schools[19]. Access to some of those material is vey essential for young learners to distinguish between different sounds. More importantly, learners are more likely to sound out the word they hear or read in an accurate way, even it is said or read quickly in a word, phrase or sentence. Some children may take longer than others to develop critical literacy skill. It's easier to start by having your child listen for the first sound in a word, and then try listening for the end sounds, as the middle sound of a word is the hardest to hear. It's proved to be a good idea to say a word and tap out the sounds. Young learners should never forget that practice does make perfect in English phonic learning.

The Clear Pronunciation through Listening Practice. It's true that every English learners in China has learned the ABC songs, but the question is whether everyone of them has the ability to sing this song with clear pronunciation. If not, there is a long way for them to go to pronounce words, phrases and sentences in a clear, accurate and most importantly understandable way. After mastering of the knowledge of phonics, young learners are enabled to distingguish and recognize different phonemes and furthermore to pronounce them out like native speakers do. A phoneme is called phoneme because it consist of several phonetically distinct articulations and one articulation may be substituted for another without any change of meaning[20]. If the phonemes of the sounds are not successfully learned by Chinese learners, native speakers will quite possibly have hard time understanding every word uttered by them. Only if a child knows the proper sounds of the alphabet letters, he or she can later use those sounds to sound out or decode more words, phrases or sentences. This step is very important because poor performance in pronunciation may have negative effect on the ability in listening and speaking. After all, we can't expect kids to understand the sound of a word in listening if they even doesn't know how to pronounce it by themselves. In this regard, the more accurately the sounds are taught to children, the easier it will be for them to learn to speak and listen, and even read and spell for successful learning later on.

The Word Cognition through Audio Material. Chinese learners may have a headache when memorizing new words with dictionary. The chances may be that learners are successful in knowing the meaning of the words in reading with the help of their spellings, but are totally at lost when recognizing the sounds of the words in listening. Although vocabulary is increased greatly through repetitive practice, but it doesn't mean one is finished with the word learning. The truth is that school-age children never pay special attention to that part. That's why English learners in China are slated to be deaf and 
dumb in the scenario of multicultural communication due to their inability to understand others and express themselves[21]. Actually, the easiest way to know how to spell a word is to listen for the sounds in that word. Understanding of letter sounds can help even with the difficult words because strategies for tricky spellings and challenging puzzles in phonic learning can be easily provided. In order to maintain the interests of English learners whilst listening, children should be able to practice it in audio material coming in different levels, easy, medium or hard, ideal for children at all levels of early learners. Teachers and parents should keep track of kids' progress and help them study smarter, step by step.

The Increased Vocabulary through Autonomous Reading. The phonemic awareness is the foundation of a child's reading ability - if a child can't hear the individual sounds in a word, he will always struggle to figure out the letters in that word[22]. Children are expected to learn how to use the letter sounds to read and write words. By introducing children to phonetically spelled words and word families, they begin to recognize familiar spelling patterns. They learn to decode by analogy. Native speakers do well in this part because they are more familiar with word sounds rather than word forms [23]. If learners have a poor memory for symbols and words, it's not easy for children to learn the blend sounds in reading. EFL learners not possessing a wealthy store of phonemes in different words are just struck with this tricky situation[24]. Then how does phonics make sense to EFL learners? With multiple word exposures in reading, school-age children are easy to gain a large vocabulary in contexts without being much effortful[25]. Extra practice will lead to fluency in reading and help kids manage in learning place. If interest is being lost, leave the learning for a while and then come back to it later. Try to find more personalized reading material for each EFL learner with carefully controlled vocabulary, so that learning can be fun and easy for them. If Chinese school-age children do listen a lot and master abundant speech sounds in vocabulary, they may become competent readers much sooner, and can use all these letter sounds to produce more expressive independent writing at a much earlier stage.

\section{Epilogue}

It has been argued that phonics may be interpreted from three areas of learning: letters and sounds, words and activities, reading and success. The main significance of English phonics learning among Chinese school-age children are different from that among native young learners, exerting positive effects on two aspects of learning performance, which are enhancing phoneme and phonemic awareness as well as boosting listening and speaking confidence among Chinese school-age children. In this regard, the intrinsic logics of cultivating English phonics among Chinese school-age children is supposed to obey to four basic rules for success in phonics learning, that is, the input of phonemes through phonics drill, the clear pronunciation through listening practice, the word cognition through audio material, and the increased vocabulary through autonomous reading. It's hoped that this research provides a useful reference for future phonics instruction and learning practice among young English language students in China.

\section{Acknowledgements}

This work is part of the project of On Intrinsic Logics, Main Implications and Intervetnion Reserach of English Phonics Enlightenment among Chinese School-age Children. This research was supported by the fund of Liaoning Planning of Philosophy and Social Science (Project No. L17CYY005).

\section{References}

[1][2] NSW Department of Education and Training. Literacy teaching guide: Phonics, 2009.

[3][4][11]About Learning to Read with Phonics. Information on https://www.kizphonics.com/what-is-phonics/

[5]Natural, holistic manipulatives build decoding and blending skills. Information on http://readskill.com/Resources/LiteracySkills/TipsDecoding.htm 
[6] Phonics blending. Information on https://www.mobymax.com/curriculum/phonics-blending

[7][8] T.G. Sticht, J.H. James. Listening and reading. In P.D. Pearson (Ed.), Handbook of reading research. New York: Longman, 1984.

[9][10][15] H.H. Ren, C. Ma. Study on the practice of phonics in English vocabulary teaching for primary school students. In J. Wang, N. Xin and H. Y. Zhou (eds.). Advances in Computer Science Research v 59. Paris: Atlantis Press. December 2016, pp.1095-1099.

[12]All about phonemes, phonetics and spelling. Information on http://www.phonemicchart.com/what/

[13] [14] H. H. Ren, C. Ma. The impact of Phonics instruction on pre-school learners' development in English language course. In J. Wang, N. Xin and H. Y. Zhou (eds.). Advances in Computer Science Research v 59. Paris: Atlantis Press. December 2016, pp.674-679.

[16] Lizzy. The Research on Phonics Instruction of English Words Teaching in the Primary School, Chongqing Normal University, 2006.

[17][18][21] [23][24][25] H.H. Ren, C. Ma. The Various Implications of English Phonics Learning Among Chinese School-age Children. In W. Jing, X Ning, and Z. Huiyu (eds.). Advances in Social Science, Education and Humanities Research V238. Paris: Atlantis Press. May 2018(Shenyang), pp. 491-495.

[19] H.H. Ren, C. Ma. The Main Channels of English Phonics Learning among Chinese School-age Children. In W. Jing, X Ning, and Z. Huiyu (eds.). Advances in Social Science, Education and Humanities Research V238. Paris: Atlantis Press. June 2017, pp. 274-278.

[20][22]Sound Pronunciations. Retrieved from the Information on http://www.sightwords.com/phonemic-awareness/sound-pronunciations/ 